\title{
Efeito de agrotóxicos usados na cultura do morangueiro sobre o predador Phytoseiulus macropilis (Banks) em laboratório, semicampo e campo no sul de Minas Gerais
}

\author{
Rafaela Costa* \\ Luiz Carlos Dias Rocha** \\ Juliano Antonio de Freitas*** \\ Giovani Márcio Coura Júnior**** \\ Oliveiros Miranda dos Santos***** \\ Éder Oliveira do Couto****** \\ * Tecnóloga em gestão ambiental e graduanda em agronomia do IFSULDEMINAS, campus Inconfidentes, \\ costa.rafaela23@gmail.com \\ ** Doutor em Entomologia, professor de agricultura do IFSULDEMINAS, campus Inconfidentes, \\ luiz.rocha@ifs.ifsuldeminas.edu.br \\ *** Mestrando em Entomologia/acarologia, ESALQ/USP, freitas.usp@hotmail.com. \\ **** Tecnólogo em gestão ambiental, Piracicaba, São Paulo. \\ ****** Mestre. IFSULDEMINAS, campus Inconfidentes. \\ ******* Tecnólogo em gestão ambiental do IFSULDEMINAS, campus Inconfidentes.
}

\section{Resumo}

A cultura do morangueiro apresenta grande importância para a agricultura familiar no sul de Minas Gerais devido ao elevado valor agregado e à distribuição de recursos. O ácaro-rajado (Tetranychus urticae Koch), principal praga desta cultura, é o principal dentre os artrópodes-praga do morangueiro. $\mathrm{O}$ método químico tem sido o mais adotado no controle dessa praga, mas esse método contribui para a seleção de indivíduos resistentes, contaminação de frutos e do ambiente, e ainda causa danos à saúde dos agricultores. Phytoseiulus macropilis (Banks) é um eficiente predador no controle de T. urticae e tem-se mostrado uma importante ferramenta para o manejo desta praga. No presente estudo objetivou-se avaliar o efeito de alguns produtos fitossanitários utilizados na cultura do morangueiro em sistemas de produção integrada (PIMo) sobre o predador P. macropilis, em condições de laboratório, semi-campo e campo. O bioensaio foi conduzido no Laboratório de Entomologia do Instituto Federal de Educação, Ciência e Tecnologia do Sul de Minas Gerais (IFSULDEMINAS), campus Inconfidentes. Os produtos testados, em $\mathrm{g}$ de i.a. $\mathrm{L}^{-1}$ de água foram: abamectina $(0,072)$, fempiroximato $(0,007)$ fempropatrina $(0,195)$, propargito $(0,195)$, imibenconazole $(0,030)$, azoxistrobina $(0,080)$, iprodiona $(0,750)$ e água como testemunha. As caldas dos produtos foram aplicadas diretamente sobre os predadores por meio de pulverizadores manuais calibrados, para avaliar a mortalidade dos indivíduos. Abamectina e fempiroximato foram considerados nocivos ao predador $P$. macropilis. $O$ composto Fempropatrina foi considerado como moderadamente nocivo, iprodiona foi considerado como levemente nocivo. Como produtos inócuos selecionaram-se compostos imibenconazole, azoxistrobina, propargito. Os compostos considerados seletivos ou inócuos podem ser recomendados no manejo integrado de pragas, associados com o predador $P$. macropilis. Em termos de semi-campo, todos os produtos testados para P. macropilis foram considerados seletivos. Desta forma, os testes em condições de campo foram dispensados.

Palavras-chave: Seletividade. Predador. Phytoseiulus macropilis. Produção integrada de morangueiro. Controle biológico. 
Efeito de agrotóxicos usados na cultura do morangueiro sobre o predador Phytoseiulus macropilis (Banks) em laboratório, semicampo e campo no sul de Minas Gerais

\section{Introdução}

O morangueiro é uma planta originalmente cultivada com finalidades medicinais e ornamentais, principalmente na Europa. Após cruzamento com as espécies Fragaria virginiana Mill. (originária da América do Norte) e Fragaria chiloensis (Linnaeus) Duchesne, 1766 (originária do Chile), obtiveram-se as plantas atualmente cultivadas (RESENDE et al., 1999). O cruzamento ocorreu por hibridação natural de plantas que eram cultivadas comercialmente (REBELO; BALARDIN, 1989; RESENDE et al., 1999; MALAGODI-BRAGA, 2002).

Minas Gerais aparece como o maior produtor do país, com 72 mil toneladas cultivadas em 1.790 hectares (EMATER-MG, 2011). 0 estado ainda responde por quase 55\% da produção nacional, gerando aproximadamente 26 mil empregos e envolvendo 5.900 produtores na atividade, em sua grande maioria produtores que praticam a agricultura familiar (RESENDE et al., 1999; CARVALHO, 2006). A produção total do morango no país alcança 133 mil toneladas e ocupa uma área aproximada de 3.718 hectares (EMATER-MG, 2011). Esses dados colocam o Brasil entre os dez maiores produtores de morango do mundo.

O morangueiro tem sido uma das culturas com maior utilização de pesticidas na agricultura nacional em consequência de práticas agrícolas incorretas e também de sua elevada susceptibilidade a pragas e doenças.

Dentre as pragas, o ácaro Tetranychus urticae Koch (Acari: Tetranychidae) destaca-se como principal problema enfrentado por produtores no sul de Minas Gerais (FREITAS et al., 2011a). Os ácaros destacam-se pelo seu alto potencial biótico, elevado prejuízo provocado às plantas e pela dificuldade de seu controle. Após seu ataque, as folhas apresentam certa quantidade de teia, manchas branco-prateadas na face abaxial, queda, e, como consequência, a produtividade diminui (FLECHTMANN, 1985).

Nas lavouras de morangueiros do Sul de Minas, o controle do ácaro-rajado é realizado principalmente pelo método químico e grande parte dos produtores apresenta pouco conhecimento sobre a correta utilização dos defensivos (FREITAS et al., 2011a). Desde a última década, o combate ao ácaro-rajado tem sido dificultado pela ocorrência de populações resistentes aos princípios ativos dos produtos fitossanitários mais utilizados (SATO et al., 1994). A predominância do controle químico, além de comprometer a qualidade do produto final, pode ser bastante impactante ao meio ambiente, e pode interferir na ação dos inimigos naturais que são reguladores da densidade populacional de ácaros e insetos-praga (VAN DE VRIE et al., 1972).

Nos últimos anos, ácaros predadores pertencentes à família Phytoseiidae têm recebido grande atenção devido à sua elevada capacidade de regulação de populações de ácaros-praga (MCMURTRY; CROFT, 1997; MORAES, 2002; SILVA et al., 2005). Ácaros predadores da família Phytoseiidae são os mais abundantes em cultura do morangueiro e têm como alimento básico ácaros tetraniquídeos (MCMURTRY; CROFT, 1997; MORAES, 2002). Em razão disso, diversos estudos têm sido realizados para aprimorar os conhecimentos acerca destes predadores (MCMURTRY; CROFT, 1997; MORAES, 2002; CHOI et al., 2004; FADINI et al., 2004; SILVA et al., 2005, VERONEZ et al., 2009; FREITAS et al., 2011b).

O ácaro Phytoseiulus macropilis (Banks) (Acari: Phytoseiidae) é considerado uma espécie de predador comum em diversas regiões do mundo. Segundo Moraes et al. (2004), está presente em vários países da Europa, África, e no continente Americano, sendo facilmente encontrado no sul de Minas (OLIVEIRA et al., 2005).

Estudos relacionados à biologia desse predador demonstraram que P. macropilis apresenta melhor desenvolvimento em temperaturas entre $23^{\circ} \mathrm{C}$ e $26^{\circ} \mathrm{C}$ (ALI, 1998; SILVA et al. 2005) e seu desempenho funcional é potencializado com o aumento da população da presa T. urticae (MARCHETTI; FERLA, 2004). Esses estudos demonstram seu grande potencial para o controle biológico do ácaro-rajado.

Entretanto, para viabilizar programas de manejo integrado ou de produção integrada em morangueiros, é importante que os produtos fitossanitários utilizados na cultura sejam inócuos ou seletivos aos inimigos naturais e que estudos de seletividade sejam incentivados em condições de laboratório, semi-campo e campo (WETZEL; DICKLER, 1994).

Assim, estudos relacionados aos métodos de controle de pragas são cada vez mais necessários para que se obtenham produtos de alto padrão de qualidade e livres de resíduos de agrotóxicos. 
O presente estudo teve por objetivo avaliar o impacto de produtos fitossanitários utilizados na cultura do morangueiro sobre o predador P. macropilis, em laboratório, semi-campo e campo.

\section{Material e métodos}

Os bioensaios das etapas de testes de laboratório foram realizados no Laboratório de Entomologia do Instituto Federal de Educação, Ciência e Tecnologia do Sul de Minas Gerais (IFSULDEMINAS), campus Inconfidentes, no período de março a junho de 2011.

Adultos e ninfas do ácaro-rajado foram coletados em plantas de morangueiros de cultivos comerciais da região do Vale do Rio Mogi (município de Bom Repouso, sul de Minas Gerais) e levados ao laboratório para dar início à criação de manutenção.

Foram mantidos em plantas de feijão-de-porco (Canavalia ensiformes L.) cultivadas em vasos e mantidas em casa de vegetação. As plantas de feijão-de-porco foram substituídas em intervalos regulares para garantir a qualidade do alimento fornecido aos indivíduos. Plantas novas foram dispostas ao lado de plantas atacadas para que ocorresse a migração natural do ácaro-rajado para a nova fonte alimentar, continuando, desta forma, o seu desenvolvimento.

Para a criação de P. macropilis, adultos e ninfas do predador foram adquiridos da Embrapa Meio Ambiente (localizada em Jaguariúna, São Paulo) e do Instituto Biológico de Campinas e levados ao laboratório do campus Inconfidentes. Os indivíduos foram mantidos em câmaras climáticas sob condições controladas de $25 \pm 2^{\circ} \mathrm{C}$, umidade relativa de $70 \pm 10 \%$ e fotofase de 14 horas, em folhas de plantas de feijão-de-porco, cultivadas em vasos e previamente infestadas com o ácaro-presa $T$. urticae. Para evitar a fuga dos predadores, as folhas de feijão-de-porco contendo os indivíduos foram colocadas em uma arena formada por algodão umedecido sobre uma superfície plástica, dispostos dentro de uma bandeja plástica com água (Figura 1).

Antes do início dos experimentos, espécimes dos ácaros praga e do predador foram montados em lâminas e enviados a especialista para identificação.

Figura 1. Sistema de criação de manutenção dos ácaros predadores Phytoseiulus macropilis, em folhas de feijãode-porco, sobre arena de algodão úmido em bandejas plásticas.

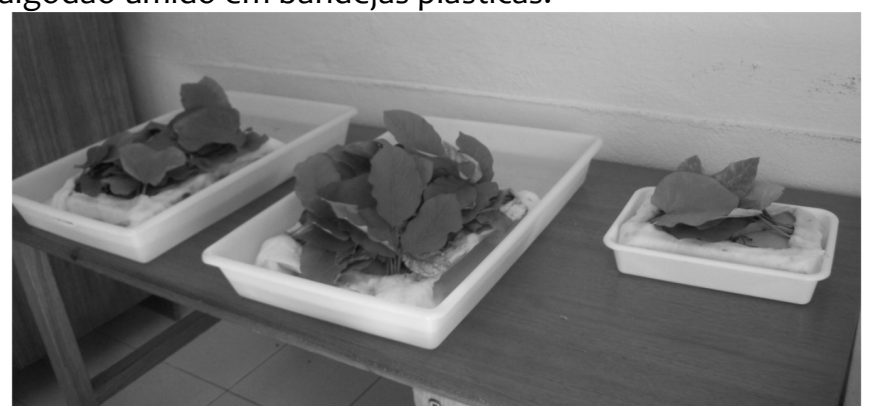

Fonte: Elaboração própria.

\subsection{Condução dos bioensaios}

Avaliou-se o efeito de compostos recomendados para uso na cultura do morangueiro e por serem produtos utilizados na região sul de Minas Gerais (Tabela 1). 0 tratamento testemunha foi composto apenas por água destilada.

As aplicações dos produtos em fêmeas adultas de $P$. macropilis foram realizadas conforme metodologia recomendada pela International Organization for Biological and Integrated Control of Noxious Animals and Plants (IOBC), West Palaearctic Regional Section (WPRS) (STERK; VANWESTSWINKEL, 1988; HASSAN, 1992; HASSAN 1994; VEIRE et al., 1996; HASSAN, 1997; DEGRANDE et al., 2002). As pulverizações dos produtos foram realizadas por meio de pulverizadores manuais de $500 \mathrm{~mL}$ previamente calibrados, assegurando a aplicação de 1,5 a 2,0 $\mathrm{mg}$ de calda. $\mathrm{cm}^{-2}$. 
Efeito de agrotóxicos usados na cultura do morangueiro sobre o predador Phytoseiulus macropilis (Banks) em laboratório, semicampo e campo no sul de Minas Gerais

Vinte e cinco fêmeas adultas de P. macropilis com até 48 horas de idade, por tratamento, oriundas da criação em laboratório, foram acondicionadas em placas de Petri de $15 \mathrm{~cm}$ de diâmetro, fechadas com filme plástico de PVC e levadas para receberem os compostos via pulverização.

Após a pulverização, os indivíduos foram separados em 8 grupos com 6 indivíduos de P. macropilis, e distribuídos sobre um disco foliar de feijão-de-porco de $4 \mathrm{~cm}$ de diâmetro, infestado com a presa $T$. urticae. $\mathrm{O}$ disco foliar foi colocado sobre uma camada de algodão hidrófilo dentro de uma placa de Petri de $9 \mathrm{~cm}$ de diâmetro, fechada com filme plástico de PVC. A camada de algodão foi umedecida diariamente (Figura 2). As placas foram mantidas em sala climatizada e sob condições controladas de $25 \pm 2^{\circ} \mathrm{C}$, umidade relativa de $70 \pm 10 \%$ e fotofase de 12 horas.

Tabela 1. Produtos fitossanitários utilizados para a avaliação do impacto sobre Phytoseiulus macropilis em condições de laboratório e semi-campo.

\begin{tabular}{lcccc}
\hline \multicolumn{1}{c}{ Ingrediente ativo } & Produto Comercial & $\begin{array}{c}\text { Concentração/ } \\
\text { Formulação }\end{array}$ & $\begin{array}{c}\text { Dose g i.a. } \text { L }^{-1} \\
\text { água }\end{array}$ & Grupo Químico \\
\hline Abamectina $^{1}$ & Vertimec & $18 \mathrm{CE}$ & 0,072 & Avermectina \\
Fempiroximato $^{1}$ & Ortus & $50 \mathrm{SC}$ & 0,007 & Pirazol \\
Fempropatrina $^{1}$ & Danimem & $300 \mathrm{CE}$ & 0,195 & Piretróide \\
Propargito & Omite & $720 \mathrm{EC}$ & 0,216 & Sulfito de alquila \\
Imibenconazole & Manage & $150 \mathrm{PM}$ & 0,015 & Milbemicinas \\
Azoxistrobina & Amistar & $500 \mathrm{WG}$ & 0,160 & Strobilurinas \\
Iprodiona & Rovral & $500 \mathrm{SC}$ & 0,750 & Dicarboximida \\
\hline
\end{tabular}

${ }^{1}$ Produtos fitossanitários testados sobre P. macropilis em condições de semi-campo.

Fonte: Elaboração própria.

O delineamento foi inteiramente casualizado com oito tratamentos e cinco repetições, constituídas de seis indivíduos de P. macropilis cada.

Após as pulverizações dos produtos, foi registrado o número de ácaros mortos de P. macropilis. A mortalidade dos ácaros foi avaliada com auxílio de um microscópio estereoscópico (40x). Foi considerado morto o indivíduo que se manteve imóvel ao estímulo gerado pelo toque de um pincel. As avaliações foram realizadas até o quinto dia após a aplicação.

Figura 2. Vista parcial do arranjo experimental em placas de Petri com arenas em folhas de Canavalia ensiformes rodeada por algodão úmido, contendo os ácaros predadores tratados com os produtos fitossanitários.

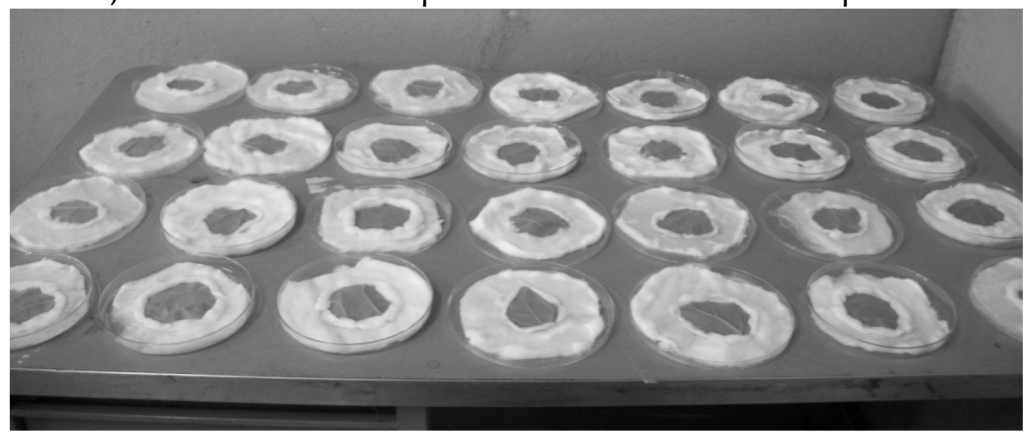

Fonte: Elaboração própria.

\subsection{Efeito dos produtos fitossanitários sobre $P$. macropilis em semi-campo}

O experimento foi realizado de acordo com a metodologia proposta pela IOBC,no período de maio a setembro de 2011. Foram utilizados apenas os compostos que, nos experimentos em laboratório, foram classificados como moderadamente nocivos ou nocivos ao predador, seguindo recomendações de Bakker et al. (1992). Em plantas de morangueiro da cultivar 'Oso Grande', com idade uniforme (70 dias após transplantio), cultivadas em vaso, utilizando substrato Plantimax misturado com solo de barranco (Latossolo Vermelho) na proporção de 1:1, foram pulverizadas as caldas dos produtos fitossanitários até o ponto de escorrimento. Os produtos foram aplicados utilizando um pulverizador 
manual de $500 \mathrm{~mL}$, que foi previamente calibrado para garantir a uniformidade na aplicação. Em seguida, as plantas foram acondicionadas em casa de vegetação.

Cerca de uma hora após a aplicação, foram distribuídas em cada planta tratada três gaiolas de PVC, nos terços superior, médio e inferior, respectivamente, sendo uma gaiola por folha. As gaiolas foram de $3 \mathrm{~cm}$ de diâmetro e $1 \mathrm{~cm}$ de altura, fechadas na parte superior com tecido de nylon para evitar a fuga dos indivíduos e aberta na parte inferior para permitir o contato dos ácaros com a superfície foliar tratada. Novas gaiolas foram colocadas nas plantas após 7, 14, 21, 28 e 31 dias a partir da pulverização das caldas (HASSAN, 1997). Em cada gaiola foram liberadas 5 fêmeas de P. macropilis e também os ácaros-presa T. urticae como fonte de alimento. Retirou-se a gaiola 120 horas após o contato dos predadores com a superfície contaminada, e avaliou-se a sobrevivência dos espécimes.

O experimento foi conduzido em esquema de blocos ao acaso, composto por 4 tratamentos e 8 repetições.

\subsection{Efeito dos produtos fitossanitários sobre $P$. macropilis em condições de campo}

Os testes de campo foram dispensados, tendo em vista que todos os compostos testados em condições de semi-campo apresentaram baixa toxicidade (classe 1 ou 2 da escala IOBC).

\subsection{Análises estatísticas}

Os dados referentes à mortalidade acumulada dos indivíduos $1 \mathrm{~h}, 24 \mathrm{~h}, 48 \mathrm{~h}, 72 \mathrm{~h}, 96 \mathrm{~h}$ e 120 horas após aplicação direta, foram submetidos à análise de variância em um modelo de parcelas subdivididas no tempo, com os produtos na parcela. Empregou-se o programa SISVAR (FERREIRA, 2011).

Nos casos em que o teste $\mathrm{F}$ foi significativo, usou-se o teste de Tukey, a 5\% de significância, para comparar as médias dos tratamentos.

\subsection{Classificação dos produtos segundo escala de toxicidade estabelecida pela IOBC}

Em função da mortalidade causada pelos produtos às fêmeas tratadas, foi calculado o efeito total (E\%) utilizando a equação proposta por Bakker et al. (1992):

$\mathrm{E}=100 \%-(100 \%-\mathrm{Ma})$

Em que: $\mathrm{E}=$ efeito total (\%) e $\mathrm{Ma}=$ mortalidade corrigida em função do tratamento testemunha (ABBOTT, 1925), em que: $\mathrm{Ma}=(\mathrm{Mt}-\mathrm{Mc}) /(100-\mathrm{Mc}) \times 100(\mathrm{Mt}=$ mortalidade observada no tratamento com o produto, $\mathrm{Mc}=$ mortalidade observada no tratamento testemunha).

a) testes em laboratório: os produtos foram enquadrados em classes conforme a porcentagem de efeito total observado em: classe $1=$ inócuos $(\mathrm{E}<30 \%)$, classe $2=$ levemente nocivos $(30 \% \leq \mathrm{E} \leq 80 \%)$, classe $3=$ moderadamente nocivos $(80 \%<\mathrm{E} \leq 99 \%)$ e classe $4=$ nocivos $(\mathrm{E}>99 \%)$, conforme escala proposta pela IOBC/WPRS (BAKKER et al., 1992; VEIRE et al., 1996; HASSAN 1997; DEGRANDE et al., 2002).

b) testes em semi-campo: em função da toxicidade apresentada por cada produto, o mesmo foi classificado em uma das seguintes categorias, de acordo com Hassan (1997): A = vida curta ( 5 dias), $\mathrm{B}=$ pouco persistente ( 5 a 15 dias $), \mathrm{C}=$ moderadamente persistente $(16$ a 30 dias $)$ e $\mathrm{D}=$ persistente $(>$ 30 dias).

\section{RESULTADOS E DISCUSSÃO}

3.1 Efeito dos produtos fitossanitários pulverizados diretamente sobre P. macropilis

Os resultados obtidos a partir do efeito causado após as pulverizações diretas dos predadores $P$. macropilis com os produtos fitossanitários após 1, 24, 48, 72, 96 e 120 horas são apresentados na Tabela 2.

Diversos autores já relataram a ação do princípio ativo abamectina sobre artrópodes, que 
Efeito de agrotóxicos usados na cultura do morangueiro sobre o predador Phytoseiulus macropilis (Banks) em laboratório, semicampo e campo no sul de Minas Gerais

proporciona efeito calmante, semelhante ao ácido gama-aminobutírico (GABA) (CLELAND, 1996). Os estudos têm demonstrado também que as avermectinas podem atuar sobre proteínas dos canais de cloro encontradas em artrópodes, elevando a especificidade e proporcionando efeito sobre insetos e ácaros (SCOTT; DUCE, 1987; MARTIN; PENNINGTON, 1988, MARTIN et al., 2002). Acredita-se que, no presente estudo, o composto pode ter provocado redução das atividades do predador, além da redução do metabolismo, provocando a mortalidade dos espécimes.

A ação do princípio ativo fempiroximato proporciona a inibição do transporte elétrico mitocondrial com a ação de contato. Neste contexto, no presente estudo, o composto pode ter provocado a inibição do transporte elétrico mitocondrial devido à ação de contato ocasionando a morte destes indivíduos PPDB (1991).

Fempiroximato, abamectina e fempropatrina provocaram elevada mortalidade dos predadores com médias de 100,0, 100,0 e 84,0\%, respectivamente, após $120 \mathrm{~h}$ de contato (Tabela 2) e foram considerados nocivos (Classe 4) a esse inimigo natural (Tabela 3). Imibenconazole, azoxistrobina e propargito causaram baixa mortalidade 120 horas após o contato, evidenciando baixa toxicidade aos predadores (Tabela 2).

Tabela 2. Mortalidade (\%) de adultos de Phytoseiulus macropilis após 1, 24, 48, 72, 96 e 120 horas, desde a aplicação dos produtos fitossanitários. Temperatura de $25 \pm 2^{\circ} \mathrm{C}$ e UR de $70 \pm 10 \%$.

\begin{tabular}{|c|c|c|c|c|c|c|}
\hline \multirow{2}{*}{ Tratamentos } & \multicolumn{6}{|c|}{ Mortalidade (\%) } \\
\hline & 1 hora & 24 horas & 48 horas & 72 horas & 96 horas & 120h \\
\hline Fempiroximato & $32,0 \mathrm{~b}$ & $48,0 \mathrm{~b}$ & $92,0 \mathrm{C}$ & $96,0 \mathrm{C}$ & $96,0 \mathrm{~d}$ & $100,0 \mathrm{C}$ \\
\hline Imibenconazole & $4,0 \mathrm{a}$ & $16,0 \mathrm{a}$ & $24,0 \mathrm{a}$ & $28,0 \mathrm{a}$ & $28,0 \mathrm{~b}$ & $28,0 \mathrm{a}$ \\
\hline Abamectina & $52,0 \mathrm{~b}$ & $64,0 \mathrm{~b}$ & $68,0 \mathrm{~b}$ & $84,0 \mathrm{C}$ & $96,0 \mathrm{~d}$ & $100,0 \mathrm{C}$ \\
\hline Azoxistrobina & $0,0 \mathrm{a}$ & $4,0 \mathrm{a}$ & $16,0 \mathrm{a}$ & $20,0 \mathrm{a}$ & $24,0 \mathrm{~b}$ & $24,0 \mathrm{a}$ \\
\hline Propargito & $12,0 a$ & $12,0 \mathrm{a}$ & $24,0 a$ & $32,0 \mathrm{a}$ & $40,0 \mathrm{~b}$ & $40,0 \mathrm{a}$ \\
\hline Fempropatrina & $20,0 \mathrm{a}$ & $60,0 \mathrm{~b}$ & $68,0 \mathrm{~b}$ & $76,0 \mathrm{~b}$ & $80,0 \mathrm{C}$ & $84,0 \mathrm{~b}$ \\
\hline Iprodiona & $8,0 \mathrm{a}$ & $36,0 \mathrm{~b}$ & $56,0 \mathrm{~b}$ & $64,0 \mathrm{~b}$ & $64,0 \mathrm{C}$ & $68,0 \mathrm{~b}$ \\
\hline Testemunha & $0,0 \mathrm{a}$ & $0,0 \mathrm{a}$ & $4,0 \mathrm{a}$ & $8,0 \mathrm{a}$ & $8,0 \mathrm{a}$ & $12,0 \mathrm{a}$ \\
\hline $\mathrm{CV}(\%)$ & 111,3 & 65,2 & 39,3 & 28,8 & 26,4 & 26,8 \\
\hline
\end{tabular}

*Médias seguidas pela mesma letra minúscula na coluna não diferem entre si pelo teste de Tukey a $5 \%$ de significância.

Fonte: elaboração própria.

\subsection{Classificação dos produtos quanto ao efeito total no $P$. macropilis, segundo escala de toxidade estabelecida pela IOBC.}

Em estudos realizados por Reis et al. (1998), o composto fempiroximato também provocou $100 \%$ de mortalidade em Iphiseiodes zuluagai (Acari: Phytoseiidae), sendo considerado nocivo a esta espécie. o composto fempropatrina foi considerado como moderadamente nocivo (Classe 3). Veronez et al. (2009), estudando os efeitos de pesticidas sobre inimigos naturais, constataram que abamectina provocou alta taxa de mortalidade de $P$. macropilis quando submetido à aplicação direta. Veronez et al. (2011) também verificaram altos índices de mortalidade de P. macropilis na utilização dos compostos abamectina e fempiroximato. 
Tabela 3. Efeito de produtos fitossanitários sobre a mortalidade (\%) de Phytoseiulus macropilis tratados na fase adulta, efeito (E) (\%) e classificação pela escala de toxicidade proposta pela IOBC. Temperatura de $25 \pm 2^{\circ} \mathrm{C}$, UR de $70 \pm 10 \%$ e fotofase de 12 horas.

\begin{tabular}{lccccc}
\hline Tratamentos & $\mathbf{N}^{\circ}$ de indivíduos & $\begin{array}{c}\text { Mortalidade } \\
(\%)\end{array}$ & MA (\%) & E(\%) $)^{\mathbf{1}}$ & Classe $^{3}$ \\
\hline Fempiroximato & 25 & 100,0 & 100,00 & 100,00 & 4 \\
Imibenconazole & 25 & 28,0 & 18,18 & 18,18 & 1 \\
Abamectina & 25 & 100,0 & 100,00 & 100,00 & 4 \\
Azoxistrobina & 25 & 24,0 & 11,36 & 11,36 & 1 \\
Propargito & 25 & 40,0 & 31,82 & 31,82 & 2 \\
Fempropatrina & 25 & 84,0 & 81,82 & 81,82 & 3 \\
Iprodiona & 25 & 68,0 & 63,64 & 63,64 & 2 \\
Testemunha & 25 & 12,0 & - & - & - \\
\hline
\end{tabular}

${ }^{1}$ A mortalidade foi corrigida conforme a fórmula: $\mathrm{Ma}=(\mathrm{Mt}-\mathrm{Mc}) /(100-\mathrm{Mc}) \times 100 ; \mathrm{ABBOTT}$ (1925)

${ }^{2}$ Efeito total do produto sobre o inimigo natural, onde: $E=100 \%$ - (100\% - Ma);

${ }^{3}$ Classe de toxicidade: classe $1=$ Inócuo $(E<30 \%$ ), classe $2=$ levemente nocivo ( $30 \% \leq E \leq 80 \%$ ), classe $3=$ moderadamente nocivo ( $80 \%<E \leq 99 \%)$ e classe $4=$ nocivo (E>99\%) (VEIRE et al., 2002).

Fonte: elaboração própria.

O composto fempropatrina foi considerado moderadamente nocivo (Classe 3). Enquanto iprodiona foi considerado levemente nocivo (Classe 2) ao predador P. macropilis, podendo ser associado em programas de PIMo no sul de Minas Gerais. Os compostos imibenconazole, azoxistrobina, propargito foram considerados inócuos (Classe 1) aos predadores, podendo assim ser associados a P. macropilis em programas de PIMo no sul de Minas (Tabela 3).

Abamectina e fempiroximato foram considerados nocivos ao predador, sendo enquadrados na classe 4, quando pulverizados diretamente sobre os espécimes. Fempropatrina foi considerado moderadamente nocivo (classe 3). Iprodiona foi considerado levemente nocivo e enquadrado na classe 2. Os compostos imibenconazole e azoxistrobina, mostraram-se inócuos aos espécimes tratados (Classe 1) (Tabela 3).

Em estudos realizados por Carvalho et al. (2011) sobre toxicidade de acaricidas a ovos e adultos de Ceraeochrysa cubana (Hagen, 1861) (Neuroptera: Chrysopidae), abamectina e fempropatrina foram classificados respectivamente classe 1 e 2 , segundo a IOBC.

3.3 Efeito dos produtos fitossanitários no P. macropilis em condições de semi-campo

Para os testes de semi-campo, a exposição do predador aos resíduos dos compostos durante o período de 31 dias evidenciou baixo ou nenhum impacto na mortalidade dos indivíduos (Tabela 4).

Tabela 4. Porcentagem de mortalidade de adultos de Phytoseiulus macropilis em diferentes períodos de avaliação (persistência dos compostos) em condições de semi-campo e classes de toxicidade (IOBC/WPRS). Temperatura $25 \pm 5^{\circ} \mathrm{C}$; UR $70 \pm 15 \%$; fotofase de 14 horas.

Porcentagem de mortalidade/período de

\begin{tabular}{|c|c|c|c|c|c|c|c|c|c|c|c|}
\hline \multirow{3}{*}{ Tratamento } & \multicolumn{10}{|c|}{ avaliação/classificação IOBC } & \multirow{3}{*}{$\begin{array}{c}\text { Classificação } \\
\text { final }^{2}\end{array}$} \\
\hline & \multicolumn{2}{|l|}{$7^{\circ} \mathrm{dia}$} & \multicolumn{2}{|c|}{$14^{\circ} \mathrm{dia}$} & \multicolumn{2}{|c|}{$21^{\circ} \mathrm{dia}$} & \multicolumn{2}{|c|}{$28^{\circ}$ dia } & \multicolumn{2}{|c|}{$31^{\circ}$ dia } & \\
\hline & $M^{1}$ & $\mathrm{C}^{2}$ & $M^{1}$ & $C^{2}$ & $M^{1}$ & $C^{2}$ & $M^{1}$ & $\mathrm{C}^{2}$ & $M^{1}$ & $C^{2}$ & \\
\hline Fempiroximato & 42,0 & B & 35,5 & B & 19,3 & A & 17,3 & A & 14,3 & A & Pouco Persistente \\
\hline Abamectina & 22,0 & $A$ & 15,5 & $A$ & 18,5 & A & 14,5 & $A$ & 18,5 & $A$ & Vida curta \\
\hline Fempropatrina & 31,3 & B & 30,0 & B & 4,4 & A & 6,4 & A & 0,0 & $A$ & Pouco persistente \\
\hline Testemunha & 13,0 & - & 0,0 & - & 2,4 & - & 3,1 & - & 0,0 & - & - \\
\hline
\end{tabular}

1 Porcentagem de mortalidade de fêmeas de Phytoseiulus macropilis.

${ }^{2}$ Classe de toxicidade dos compostos em condições de semi-campo (HASSAN, 1997): A = vida curta ( $<5$ dias), B = pouco persistente ( 5 a 15 dias), $C=$ moderadamente persistente ( 16 a 30 dias) e $D=$ persistente ( $>30$ dias).

Fonte: elaboração própria. 
Fempiroximato e Fempropatrina apresentaram-se mais prejudiciais na primeira semana de avaliação, provocando mortalidades de 42,0 e $31,3 \%$, respectivamente. O efeito evidenciado na primeira semana foi também constatado no $14^{\circ}$ dia. Não foi verificado nenhum efeito prejudicial nas demais avaliações, e os compostos testados não diferiram do tratamento testemunha, sendo os compostos enquadrados como pouco persistentes (Tabela 4). Abamectina, na concentração testada, não provocou nenhum efeito sobre a mortalidade de $P$. macropilis em condições de semi-campo e foi considerado produto de vida curta em condições de semi-campo.

\section{Conclusão}

Os compostos abamectina e fempiroximato foram prejudiciais ao predador P. macropilis, sendo considerados como nocivos para aplicação direta em condições de laboratório.

o composto fempropatrina ocasionou alta taxa de mortalidade, sendo considerado moderadamente nocivo ao predador P. macropilis.

Os compostos propargito e iprodiona foram considerados como levemente nocivos aos predadores P. macropilis em laboratório.

Em condições de semi-campo, nenhum dos compostos testados foi prejudicial para a espécie de predador estudada.

Imibenconazole, azoxistrobina e propargito foram seletivos a P. macropilis em laboratório.

A associação de produtos de baixa toxicidade aos predadores $P$. macropilis em manejo integrado pode representar uma boa estratégia no controle do ácaro-rajado em cultivos de morangueiro, além de representar um importante mecanismo para proteção do meio ambiente e redução do impacto ambiental, considerando principalmente as situações de maiores densidades populacionais das pragas.

\section{Agradecimentos}

Os autores agradecem o apoio especial da Fundação de Amparo a Pesquisa do Estado de Minas Gerais (FAPEMIG) pelos recursos financiadores que possibilitaram a realização desse projeto.

Os autores agradecem também o apoio das instituições parceiras (Emater, Embrapa, Instituto Biológico, Esalq, Epamig e IMA) e produtores de morango, que juntos buscam o desenvolvimento sustentável da cultura.

\section{Effect of pesticides used in strawberry crop on predator Phytoseiulus macropilis (Banks) in laboratory, semifield and field in the south of Minas Gerais}

\section{Abstract}

The strawberry crop has great importance for family farmers in southern Minas Gerais by the high value-added and tecnology used. Among the arthropod pests of strawberry has the spider mite (Tetranychus urticae Koch), the main pest of this crop. The chemical control has been used, which contributes to the selection of resistant populations, environmental pollution and damage to fruits and even the health of farmers. Phytoseiulus macropilis (Banks) is an efficient predator to control $T$. urticae and has proved an important tool for the management of this pest. In the present study aimed to evaluate the effect of some pesticides used in strawberry crop in integrated production systems 
(PIMO) on the predator P. macropilis under laboratory conditions, semi-field and field. The bioassay was conducted at the Laboratory of Entomology of the Federal Institute of Education, Science and Technology in South Minas Gerais (IFSULDEMINAS) Campus Inconfidentes - MG. The products tested in $g$ a.i. $\mathrm{L}^{-1}$ of water, were abamectin (0.072), fenpyroximate (0.007), fenpropathrin (0.195), propargite (0.195), imibenconazole (0.030), azoxystrobin (0.080), iprodione (0.750) and water as control. The products were sprayed directly on predatory mites, using calibrated sprayers. The parameter evaluated was the mortality of predatory mites. Fenpyroximate and abamectin were considered harmful to the predator P. macropilis. The compound fenpropathrin was considered moderately harmful and iprodione was considered slightly harmful. As products harmless compounds are selected imibenconazole, azoxystrobin, propargite. The compounds selective or innocuous may be recommended in integrated pest management, associated with the predator $P$. macropilis. In terms of semi-field, all products tested on P. macropilis were classified as selective. Thus, the tests under field conditions was provided.

Key words: Selectivity. Predator. Phytoseiulus macropilis. Integrated production of Strawberry. Biological Control.

\section{Referências bibliográficas}

ABBOTT, W. S. A method of computing the effectiveness of an insecticide. Journal of Economic Entomology, Lanham, v. 15, n. 2, p. 265-267, 1925.

ALI, F. S. Life tables of Phytoseiulus macropilis (Banks) (Gamasida: Phytoseiidae) at different temperatures. Experimental Applied Acarology, Amsterdã, v. 22, n. 6, p. 335-342, jun. 1998.

BAKKER, F. et al. Side-effect tests for Phytoseiids and their rearing methods. In: INTERNATIONAL ORGANIZATION FOR BIOLOGICAL CONTROL OF NOXIOUS ANIMALS AND PLANTS. Working Group "Pesticides and Beneficial Organisms". Bulletin SROP, Montfavet, v. 15, n. 3, p. 61-81, 1992.

CARVALHO, G. A.; CARVALHO, C. F.; FERREIRA, M. N. Toxicidade de acaricidas a ovos e adultos de Ceraeochrysa cubana (Hagen, 1861) (Neuroptera: Chrysopidae). Ciência e Agrotecnologia, Lavras, v. 35, n. 1, p. 165-171, jan./fev. 2011. Disponível em:

$<$ http://www.scielo.br/scielo.php?script=sci_arttext\&pid=S1413-

70542011000100021\&lng=en\&nrm=iso>. Acesso em: 27 set. 2012. DOI:

http://dx.doi.org/10.1590/S1413-70542011000100021

CARVALHO, S. P. Boletim do morango: cultivo convencional, segurança alimentar, cultivo orgânico. Belo Horizonte: FAEMG, 2006.

CHOI, W. et al. Toxicity of plants oils to Tetranychus urticae (Acari: Tetranychidae) and Phytoseiulus persimilis (Acari: Phytoseiidae). Journal Economic Entomology, [s.l], v. 97, n. 2, p. 353-358, abr. 2004.

CLELAND, T. A. Inhibitory glutamate-receptor channels. Molecular Neurobiology, Firenze, v. 13, n. 2, p.97-136, out. 1996.

DEGRANDE, P. E. et al. Metodologia para avaliar o impacto de pesticidas sobre inimigos naturais. In: PARRA, J. R. P. et al. Controle biológico no Brasil: parasitoides e predadores. São Paulo: Manole, 2002. p. 71-94.

EMATER-MG - EMPRESA DE ASSISTÊNCIA TÉCNICA E EXTENSÃO RURAL DO ESTADO DE MINAS GERAIS. Disponível em

<http://www.emater.mg.gov.br/portal.cgi?flagweb=site_tpl_paginas_internas\&id=7916>. Acesso em: 22 set. 2011. 
Efeito de agrotóxicos usados na cultura do morangueiro sobre o predador Phytoseiulus macropilis (Banks) em laboratório, semicampo e campo no sul de Minas Gerais

FADINI, M. A. M.; PALLINI, A.; VENZON, M. Controle de ácaros em sistema de produção integrada de morango. Revista Ciência Rural, Santa Maria, v. 34, n. 4, p. 1271-1277, jul./ago. 2004.

FERREIRA, D. F. SISVAR: a computer statistical analysis system. Revista Ciência e Agrotecnologia, Lavras, v.35, n.6, p.1039-1042, nov./dez., 2011.

FLECHTMANN, C. H. W. Ácaros de importância agrícola. São Paulo: Livraria Nobel, 1985.

FREITAS, J. A. et al. Produtores de morango no município de Bom Repouso relatam Tetranychus urticae Koch como principal problema da cultura. In: SIMPÓSIO BRASILEIRO DE ACAROLOGIA, 3, 2011. Campinas. Resumos... São Paulo: 3, 2011a. p. 1.

FREITAS, J. A. et al. Efeito da aplicação direta dos produtos fitossanitários utilizados na cultura do morangueiro sobre os predadores Neoseiulus californicus em condições de laboratório. In: Jornada Científica e Tecnológica, 3, 2011. Machado. Resumos... Minas Gerais: 3, 2011b. p. 1.

HASSAN, S. A. Guideline for the evaluation of side-effects of plant protection product on Trichogramma cacoeciae. In: INTERNATIONAL ORGANIZATION FOR BIOLOGICAL CONTROL OF NOXIOUS ANIMALS AND PLANTS. Working Group "Pesticides and Beneficial Organisms". Bulletin SROP, Montfavet, v.15, n.3, p.18-39, Apr. 1992.

HASSAN, S. A. Métodos padronizados para testes de seletividade com ênfase em Trichogramma. In: PARRA, J. R. P.; ZUCCHI, R. A. Trichogramma e o controle biológico aplicado. Piracicaba: FEALQ, 1997. p. 207-233.

HASSAN, S. A. Production of the angoumois grain Sitotroga cerealella (Oliv.) as alternative host for egg parasites. In: GERDING, P. M. Taller internacional producción y utilización de Trichogramma para el control biológico de plagas. Chillán: INIA/Quilamapu, 1994. p. 20-26.

MALAGODI-BRAGA, K.S. Estudo de agentes polinizadores em cultura de morango (Fragaria $x$ ananassa Duchesne - Rosaceae). 2002. 110p. Dissertação (Doutorado). Universidade de São Paulo, São Paulo.

MARCHETTI, M. M.; FERLA, N. J. Resposta funcional de Phytoseiulus macropilis Banks a diferentes populações de T. urticae Koch (Acari: Phytoseiidae e Tetranychidae). In: CONGRESSO BRASILEIRO DE ENTOMOLOGIA, 20, 2004. Gramado, RS. Anais... Gramado: Embrapa Uva e Vinho, 2004. p. 175.

MARTIN, R. J.; PENNINGTON, A. J. Effect of dihydroavermectin-b1a on CI single-channel currents in Ascaris. Pesticide Science, Sussex, v. 24, n. 1, p. 90-91, jan./fev. 1988.

MARTIN, R. J.; ROBERTSON, A. P.; WOLSTENHOLME, A. J. Macrocyclic lactones. In: VERCRUYSSE, J.; REW, R. S. Antiparasitic Therapy. [s. 1.]: CAB International, 2002.

MCMURTRY, J. A.; CROFT, B. A. Life styles of phytoseiid mites and their roles as biological control agents. Annual Review of Entomology, [s.l], v. 42, p. 291-321, jan. 1997.

MORAES, G. J. Controle biológico de ácaros fitófagos com predadores. In: PARRA, J. R. P. et al. Controle biológico no Brasil: parasitoides e predadores. São Paulo: Manole, 2002. p. 225-237.

MORAES, G. J. et al. A revised catalog of the mite family Phytoseiidae. Zootaxa, St. Johns (Nova Zelândia), v. 434, p. 1-494, fev. 2004. 
OLIVEIRA, H. G. et al. Respostas funcional e numérica do predador Phytoseiulus macropilis alimentado com ovos de Tetranychus urticae. In: SIMPÓSIO DE CONTROLE BIOLÓGICO, 9., 2005, Recife, PE. Anais..., Recife: CPqAM, UFPE, UFRPE, 2005. p. 168.

PPDB, Pesticides properties data base: fenpyroximate. Disponível em:

<http://sitem.herts.ac.uk/aeru/footprint/en/Reports/309.htm>. Acesso em: 25 set. 2011.

REBELO, J. A.; BALARDIN, R. S. A cultura do morangueiro. Florianópolis: EMPASC, 1989. 33p. (EMPASC. Boletim Técnico, 46).

REIS, P. R. et al. Seletividade de Agroquímicos ao Ácaro Predador Iphiseiodes zuluagai Denmark \& Muma (Acari: Phytoseiidae). Anais da Sociedade Entomológica do Brasil, [s.l], v. 27 n. 1, p. 265-274, jun. 1998.

RESENDE, L. M. A.; MASCARENHAS, M. H. T.; PAIVA, B. M. Panorama da produção e comercialização de morango. Informe Agropecuário, Belo Horizonte, v. 20, n. 198, p. 5-19, 1999.

SATO, M. E. et al. Resistência do ácaro-rajado Tetranychus urticae (Koch, 1836) (Acari: Tetranychidae) a diversos acaricidas em morangueiro (Fragaria sp.) nos municípios de Atibaia-SP e Piedade-SP.

Ecossistema, v. 19, p. 40-46, mai. 1994.

SCOTT, R. H.; DUCE, I. R. Pharmacology of GABA receptors on skeletal muscle fibres of the locust (Schistocerca gregaria). Comparative Biochemistry and Physiology, Oxford, v. 86, n. 2, p. 305-311, mai. 1987.

SILVA, F. R. et al.. Exigências térmicas e tabela de fertilidade de Phytoseiulus macropilis (Banks) (Acari: Phytoseiidae). Neotropical Entomology, Londrina, v. 34, n. 2, p. 291-296, 2005.

STERK, G.; VANWETSWINKEL, G. A field method for testing for the side-effects of pesticides on the predatory mite Amblyseius finlandicus (oud.) (Phytoseiidae: Acari). IOBC/WPRS. Bulletin, 1984/IX/4, p. 137, 1988.

VAN de VRIE, M.; MCMURTRY, J. A.; HUFFAKER, C. B. Ecology of tetranychid mites and their natural enemies: A review. Hilgardia, Berkeley, v. 41, p. 387-403, abr. 1972.

VEIRE, M.; SMAGGHE, G.; DEGHEELE, D. A laboratory test method to evaluate the effect of 31 pesticides on the predatory bug, Orius laevigatus (Heteroptera: Anthocoridae). Entomophaga, Paris, v. 41, n. 2, p. 235-243, fev. 1996.

VEIRE, M. van de et al. Sequential testing scheme for the assessment of the side-effects of plant protection products on the predatory bug Orius laevigatus. BioControl, Dordrecht, v. 47, n. 1, p. 101113, fev. 2002.

VERONEZ, B. et al. Toxicidade aguda de compostos sintéticos e naturais sobre adultos de Phytoseiulus macropilis (Banks) (Acari: Phytoseiidae) em laboratório. In: SIMPÓSIO BRASILEIRO DE ACAROLOGIA, 3, 2011. Campinas. Resumos... São Paulo: 3, 2011. p. 1.

VERONEZ, B. et al. Seletividade de produtos fitossanitários utilizados na cultura do morangueiro a Phytoseiulus macropilis (Banks) (Acari: Phytoseiidae) em condições de laboratório. Revista

Agrogeoambiental, Inconfidentes, v. 1, n. 2, p. 70-81, mai./ago. 2009. Disponível em: 
Efeito de agrotóxicos usados na cultura do morangueiro sobre o predador Phytoseiulus macropilis (Banks) em laboratório, semicampo e campo no sul de Minas Gerais

$<$ http://www.ifsuldeminas.edu.br/ ojs/index.php/Agrogeoambiental/article/view/79/77>. Acesso em: 26 set. 2012.

WETZEL, C.; DICKLER, E. Side effects of sulphur and a natural pyrethroid on Trichogramma dendrolimi Matsumura (Hym., Trichogrammatidae) in apple orchards. In: INTERNATIONAL ORGANIZATION FOR BIOLOGICAL CONTROL OF NOXIOUS ANIMALS AND PLANTS. Working group "pesticides and beneficial organisms. Bulletin SROP, v.17, n.10, Montfavet, 1994. p. 123-131.

\section{Histórico editorial}

Recebido: 23/05/2012

Avaliação e copidesque: 30/05/2012 a 05/11/2012

Publicação aprovada: 10/11/2012 